\title{
CHLORIDE AND CALCIUM IONS REVEAL A PHARMACOLOGICALLY DISTINCT POPULATION OF L-GLUTAMATE BINDING SITES IN SYNAPTIC MEMBRANES: CORRESPONDENCE BETWEEN BIOCHEMICAL AND ELECTROPHYSIOLOGICAL DATA ${ }^{1}$
}

\author{
G. E. FAGG, ${ }^{2}$ A. C. FOSTER, ${ }^{3}$ E. E. MENA, ANd C. W. COTMAN \\ Department of Psychobiology, University of California, Irvine, California 92717 \\ Received July 17, 1981; Revised January 25, 1982; Accepted February 5, 1982
}

\begin{abstract}
The effects of $\mathrm{Cl}^{-}$and $\mathrm{Ca}^{2+}$ on the specific binding of L-glutamate and L-aspartate to synaptic plasma membranes (SPMs) were examined. At a concentration of $2.5 \mathrm{mM}, \mathrm{CaCl}_{2}$ augmented Lglutamate binding 3.34-fold and modified its pharmacological specificity, whereas L-aspartate binding was unaffected. Kinetic analyses of the inhibition of L-glutamate binding by the $\alpha$-amino- $\omega$-phosphonic acid derivatives of propionic (APP), butyric (APB), and valeric (APV) acids demonstrated that, in the presence of $\mathrm{CaCl}_{2}$, these homologues competed for the same L-glutamate binding site with $K_{i}$ values of $16 \mu \mathrm{M}$ (APB), $39 \mu \mathrm{M}$ (APV), and >1 mM (APP); the L isomer of APB was 15-fold more potent than the $\mathrm{D}$ form ( $K_{i}$ values, 5 and $75 \mu \mathrm{M}$, respectively). Hill plots indicated an absence of cooperative interactions. These $K_{i}$ values are in close agreement with those determined electrophysiologically for the antagonism of perforant path-granule cell synaptic transmission in the rat dentate gyrus in vitro (Koerner, J. F., and C. W. Cotman (1981) Brain Res. 216: 192-198). In the presence of $\mathrm{CaCl}_{2}$, approximately $80 \%$ of the L-glutamate binding sites were sensitive to inhibition by the phosphonic acid derivatives, and experiments with APB indicated that the insensitive sites could be equated with the $\mathrm{CaCl}_{2}$-independent sites. Investigations with $\mathrm{Cl}^{-}$and $\mathrm{Ca}^{2+}$ separately and in combination suggested that $\mathrm{Cl}^{-}$is necessary to unmask the APB-sensitive sites and that $\mathrm{Ca}^{2+}$ is required to reveal the full extent of this response. Further studies showed that the $\mathrm{Cl}^{-} / \mathrm{Ca}^{2+}$. dependent APB-sensitive L-glutamate binding sites are enriched in SPMs (relative to total particulate and crude mitochondrial fractions) and that these sites are sensitive to inhibition by a number of compounds with agonist or antagonist properties at excitatory amino acid receptor sites. These data indicate that $\mathrm{Cl}^{-}$and $\mathrm{Ca}^{2+}$ unmask a pharmacologically distinct population of L-glutamate binding sites which are of physiological significance for acidic amino acid-mediated synaptic transmission in the brain.
\end{abstract}

Electrophysiological studies have demonstrated the presence of multiple excitatory amino acid receptor types on neurons of the mammalian central nervous system (CNS) ${ }^{4}$ Examination of a large number of excitants and

\footnotetext{
${ }^{1}$ We would like to thank Professors J. C. Watkins, C. H. Eugster, H. Shinozaki, and H. McLennan and Ciba-Geigy for generously providing many of the compounds used in this study and Ms. S. Bathgate and R. Stephens for their help in the preparation of the manuscript. This work was supported by fellowships from the North Atlantic Treaty Organization and the National Institutes of Health and by Grants NS 08957 and MH 19691 from the National Institutes of Health.

${ }^{2}$ To whom correspondence should be addressed.

${ }^{3}$ Present address: Neuroscience Program, Maryland Psychiatric Research Center, Baltimore, MD 21228.

${ }^{4}$ The abbreviations used are: ADCP, cis-1-amino-1,3-dicarboxycyclopentane; APB, 2-amino-4-phosphonobutyrate; APP, DL-2-amino-3-
}

their sensitivity to antagonism by $\mathrm{D}$ - $\alpha$-aminoadipate (D $\alpha \mathrm{AA})$ and glutamate diethyl ester has led to a classification scheme for these receptors based on the most selective agonists, quisqualate, $N$-methyl-D-aspartate (NMDA), and kainate; L-glutamate and L-aspartate are less specific but show some preference for the quisqualate and NMDA receptor types, respectively (see recent re-

phosphonopropionate; APV, DL-2-amino-5-phosphonovalerate; CNS, central nervous system; D $\alpha$ AA, D- $\alpha$-aminoadipate; DAP, 2,6-diaminopimelate; $\gamma$ DGG, $\gamma$-D-glutamylglycine; EDTA, ethylenediaminetetraacetate; GABA, $\gamma$-aminobutyric acid; HEPES, 4-(2-hydroxyethyl)-1pipcrazine-ethanesulfonic acid; INT, iodonitrotetrazolium violet; L $\alpha$ AA, L- $\alpha$-aminoadipate; NMA, $N$-methyl-DL-aspartate; NMDA, $N$ methyl-D-aspartate; PDA, DL-cis-2,3-piperidine dicarboxylate; SPMs, synaptic plasma membranes. 
views by Cotman et al., 1981; McLennan, 1981; Watkins and Evans, 1981). Parallel biochemical investigations are more limited, in part due to the lack of a wide range of radiolabeled ligands, although recent experiments have identified distinct binding sites for L-glutamate, L-aspartate, and kainate in synaptic membrane fractions isolated from CNS tissues (Foster and Roberts, 1978; London and Coyle, 1979; Michaelis et al., 1980; Sharif and Roberts, 1981; Foster et al., 1981b). Pharmacological analyses, however, have revealed a number of discrepancies between the sites labeled in binding assays and those examined electrophysiologically (see Roberts, 1981), and it has proven difficult to equate conclusively binding sites with physiological synaptic receptors.

One significant methodological difference between these two types of study is the composition of the assay medium. Binding assays are commonly conducted using buffers alone (e.g., HEPES-KOH or Tris-Cl), whereas electrophysiological experiments either are performed in vivo or, for in vitro work, employ a complex medium of similar ionic composition to that occurring physiologically in the cerebrospinal fluid or extracellular space. Recent investigations have demonstrated that a number of ions are capable of modifying the interaction between neurotransmitters and their receptors. For example, $\mathrm{Na}^{+}$ regulates the agonist-antagonist conformation of opiate (Pert and Snyder, 1974) and noradrenaline receptors (Greenberg et al., 1978), $\mathrm{Mg}^{2+}$ acts as an antagonist (although indirectly) at NMDA sites (Ault et al., 1980), $\mathrm{Ca}^{2+}$ appears necessary for binding at the $\gamma$-aminobutyrate (GABA) B site (Hill and Bowery, 1981), and a number of anions (notably $\mathrm{Cl}^{-}$) modify the interaction of $\mathrm{GABA}$ antagonists and benzodiazepines with their recognition sites (see Olsen, 1981). $\mathrm{Ca}^{2+}$ also has been shown to increase the number of $\mathrm{Na}^{+}$-independent L-glutamate binding sites in synaptic membranes (Michaelis et al., 1974; Baudry and Lynch, 1979; Vargas and Costa, 1981; Foster et al., 1981a, b), and this effect has been attributed to the activation of an intracellularly located membranebound protease which exposes additional binding sites (Baudry and Lynch, 1980; Vargas et al., 1980). Recent investigations in this laboratory demonstrate further that $\mathrm{Cl}^{-}$exerts a potent stimulatory effect on L-glutamate binding and that $\mathrm{Cl}^{-}$and $\mathrm{Ca}^{2+}$ act in concert to enhance the binding of this ligand (Mena et al., 1982).

In the present study, we have examined the pharmacological specificity of L-glutamate and L-aspartate binding to synaptic plasma membranes (SPMs) in the presence and absence of $\mathrm{Ca}^{2+}$ and $\mathrm{Cl}^{-}$. We present a detailed analysis of the inhibition of L-glutamate binding by a homologous series of phosphonic acid derivatives and show that the pharmacological specificity observed in the presence of $\mathrm{Ca}^{2+}$ and $\mathrm{Cl}^{-}$is similar to that determined electrophysiologically at the perforant path-granule cell synapse in the hippocampal slice in vitro (Koerner and Cotman, 1981), where glutamate is probably the neurotransmitter (Cotman and Nadler, 1981). Our data indicate (1) that there are two distinct populations of $\mathrm{Na}^{+}$independent L-glutamate binding sites in SPMs which can be distinguished on the basis of their $\mathrm{Cl}^{-}$and $\mathrm{Ca}^{2+}$ dependence and their pharmacological properties and (2) that $\mathrm{Cl}^{-} / \mathrm{Ca}^{2+}$-dependent L-glutamate binding sites are of physiological significance for acidic amino acidmediated synaptic transmission in the CNS. Preliminary results from this study have been reported elsewhere (Fagg et al., 1981; Monaghan et al., 1981).

\section{Materials and Methods}

Materials. L- $\left[3,4-{ }^{3} \mathrm{H}\right]$ glutamic acid $(40.3$ to $43.3 \mathrm{Ci} /$ mmol) was obtained from New England Nuclear (Boston, MA), and L-[U- $\left.{ }^{14} \mathrm{C}\right]$ glutamic acid (282 to $285 \mathrm{mCi} / \mathrm{mmol}$ ) and $\mathrm{L}-\left[2,3-{ }^{3} \mathrm{H}\right]$ aspartic acid $(9$ to $15 \mathrm{mCi} / \mathrm{mmol})$ were from Amersham Corp. (Arlington Heights, IL) . 4-(2-Hydroxyethyl)-1-piperazine-ethanesulfonic acid (HEPES) was purchased from Calbiochem (La Jolla, CA), and other common laboratory reagents were from Sigma (St. Louis, MO) or Mallinckrodt (St. Louis, MO).

Amino acid analogues were obtained as follows: the $\mathrm{L}$ (optical rotation $\left.[\alpha]_{\mathrm{D}}=+28.9^{\circ}\right)$ and $\mathrm{D}\left([\alpha]_{\mathrm{D}}=-29.7^{\circ}\right.$ ) isomers of 2-amino-4-phosphonobutyrate (APB), DL-2amino-5-phosphonovalerate (APV), 2,6-diaminopimelate (DAP), $\gamma$-D-glutamylglycine ( $\gamma \mathrm{DGG})$, and DL-cis-2,3-piperidine dicarboxylate (PDA) were provided by Professor J. C. Watkins (Bristol), and DL-ibotenate, DL-quisqualate, and cis-1-amino-1,3-dicarboxycyclopentane (ADCP) were from Professors C. H. Eugster (Zurich), H. Shinozaki (Tokyo), and H. McLennan (Vancouver), respectively. DL-2-Amino-3-phosphonopropionate (APP) and DL-APB were purchased from Calbiochem (La Jolla, $\mathrm{CA}$ ), and $N$-methyl-DL-aspartate (NMA), the L and $\mathrm{D}$ isomers of $\alpha$-aminoadipate (L $\alpha \mathrm{AA}$ and $\mathrm{D} \alpha \mathrm{AA}$, respectively), kainate, and GABA were obtained from Sigma (St. Louis, Mo). Baclofen ( $\gamma$-amino- $\beta$ - $(p$ chlorophenyl)butyric acid) was provided by CibaGeigy (Summit, NJ).

Isolation of synaptic plasma membranes (SPMs) and other subcellular fractions. SPMs and other subcellular fractions were isolated from rat forebrains (SpragueDawley, aged 30 to 60 days) using a modification of the method of Cotman and Taylor (1972) as recently described in detail (Foster et al., 1981a). Briefly, a crude mitochondrial $\left(\mathrm{P}_{2}\right)$ fraction was prepared, lysed using hypotonic buffer, treated with iodonitrotetrazolium violet (INT; to facilitate the separation of mitochondria from SPMs; see Cotman and Taylor, 1972), and further subfractionated by discontinuous sucrose density gradient centrifugation. The myelin (floating on $0.95 \mathrm{M}$ sucrose) and mitochondrial fractions (pellet in $1.3 \mathrm{M}$ sucrose) were discarded, and SPMs were recovered from the $0.95 \mathrm{~m} / 1.3 \mathrm{~m}$ sucrose interface. These were diluted with $0.2 \mathrm{~mm}$ HEPES-KOH buffer (pH 7.4), pelleted by centrifugation at $55,000 \times g$ for $20 \mathrm{~min}$, and then washed three more times in the same manner (resuspension in buffer and centrifugation). Each wash involved an approximately 100 -fold dilution of the pellet. In some experiments, SPMs were treated with ethylenediaminetetra-acetate (EDTA) to remove tightly bound divalent cations. In these cases, membranes were resuspended (1 $\mathrm{mg}$ of protein $/ \mathrm{ml}$ ) in a solution of $4 \mathrm{IIM}$ EDTA and 0.2 $\mathrm{mM}$ HEPES-KOH $\left(\mathrm{pH} \mathrm{7.4)}\right.$, incubated at $20^{\circ} \mathrm{C}$ for 45 min, and washed four times as described above; control membranes were incubated in the absence of EDTA and washed in the same manner.

SPMs were used for all binding assays unless otherwise 
stated. A small number of assays were performed with the total particulate, lysed $\mathrm{P}_{2}$, and INT-treated $\mathrm{P}_{2}$ (INT$\mathrm{P}_{2}$ ) fractions. In these cases, fractions were lysed osmotically and then washed three or four times as described for SPMs. All fractions were finally resuspended in 50 mM HEPES-KOH buffer ( $\mathrm{pH}$ 7.4) for storage on ice overnight (Foster et al., 1981a). The protein concentration of each fraction was determined (Lowry et al., 1951) using bovine serum albumin as standard.

Binding assays. The binding of L-glutamate and Laspartate to the membrane fractions was determined using a Microfuge assay technique (Foster et al., 1981a). Binding sites were assayed in triplicate either separately ( ${ }^{3} \mathrm{H}$-labeled compounds) or using the double label procedure $\left(\left[{ }^{3} \mathrm{H}\right]\right.$ aspartate $/\left[{ }^{14} \mathrm{C}\right]$ glutamate $)$ that we have described recently (Foster et al., 1981a). With the exception of the Scatchard analyses shown in Figure 1a, radiolabeled ligands were used at a concentration of $50 \mathrm{nM}$, and specific binding was defined as that which could be displaced by a $0.5 \mathrm{~mm}$ concentration of the nonradiolabeled ligand. $\mathrm{CaCl}_{2}(2.5 \mathrm{~mm})$ and other compounds were included in the assay buffer (50 mM HEPES-KOH, pH 7.4) as indicated under "Results."

Thin layer chromatography (cellulose plates; mobile phase 1-butanol:acetic acid:water, 12:3:5 by volume) of the radioactivity bound to SPMs showed that greater than $95 \%$ co-migrated with the parent amino acid, indicating that metabolism did not occur to any appreciable extent during the assay.

\section{Results}

Basal binding levels and the effects of $\mathrm{CaCl}_{2}$. The basal levels of $\mathrm{L}$-glutamate and L-aspartate binding in SPM fractions were $1.94 \pm 0.27 \mathrm{pmol} / \mathrm{mg}$ of protein and $0.83 \pm 0.15 \mathrm{pmol} / \mathrm{mg}$ of protein, respectively (means \pm SEM of data from 13 separate experiments; $50 \mathrm{nM}$ ligand concentration). Inclusion of $2.5 \mathrm{mM} \mathrm{CaCl}$ in the assay buffer augmented the binding of L-glutamate $3.34 \pm 0.44$ fold ( $p<0.01 ; n=13$; paired $t$ test), whereas L-aspartate binding was unchanged (1.14 \pm 0.06 -fold; $n=13 ; p>0.1$ ).

Effects of $\mathrm{CaCl}_{2}$ on the pharmacology of L-glutamate and $L$-aspartate binding. The effect of $\mathrm{CaCl}_{2}$ on the pharmacological specificity of L-glutamate and L-aspartate binding to SPMs was examined initially using a homologous series of acidic amino acid analogues-the $\alpha$-amino- $\omega$-phosphonic acid derivatives of propionic (APP), butyric (APB), and valeric (APV) acids-which exhibit activity at excitatory amino acid receptor sites in the mammalian CNS (White et al., 1979; Davies and Watkins, 1979; Davies et al., 1981; Koerner and Cotman, 1981).

Table I shows that, in the absence of added ions, the degree of inhibition of L-glutamate binding by the phosphonic acid derivatives $(0.1 \mathrm{mM}$ concentration) increased with chain length, with DL-APV the most effective of these homologues. However, in the presence of $\mathrm{CaCl}_{2}$, DL-APB was a significantly $(p<0.1)$ more effective inhibitor than in the absence of this ion such that these compounds now could be ordered APB $>$ APV $>$ APP as inhibitors of L-glutamate binding. Further experiments with the stereoisomers of APB suggested that the inhibitory activity of these compounds resided principally with
TABLE I

Inhibition of L-glutamate and L-aspartate binding to SPMs: Effects of $\mathrm{CaCl}_{2}$

SPMs were isolated from rat forebrains and specific L-glutamate and L-aspartate binding were assayed as described under "Materials and Methods." $\mathrm{CaCl}_{2}(2.5 \mathrm{~mm})$ and the inhibitory compounds being tested (0.1 $\mathrm{mm}$ final concentration) were included in the assay buffer as appropriate. The values are the means \pm SEM of data from four to seven separate experiment.s. An upward arrow indicates an increase (not inhibition) of binding.

\begin{tabular}{|c|c|c|c|c|}
\hline \multirow{3}{*}{ Compound } & \multicolumn{4}{|c|}{ Percent Inhibition of Specific Binding } \\
\hline & \multicolumn{2}{|c|}{ L-Glutamate } & \multicolumn{2}{|c|}{ L-Aspartate } \\
\hline & $\begin{array}{c}\text { Zero } \\
\mathrm{CaCl}_{2}\end{array}$ & $2.5 \mathrm{mM} \mathrm{CaCl}_{2}$ & $\begin{array}{c}\text { Zero } \\
\mathrm{CaCl}_{2}\end{array}$ & $2.5 \mathrm{mM} \mathrm{CaCl}_{2}$ \\
\hline DL-APP & $5 \pm 5$ & $8 \pm 3$ & $1 \pm 8$ & $1 \pm 6$ \\
\hline DL-APB & $23 \pm 8$ & $67 \pm 5^{a}$ & $4 \pm 4$ & $14 \pm 7$ \\
\hline DL-APV & $42 \pm 13$ & $53 \pm 6$ & $11 \pm 7$ & $5 \pm 9$ \\
\hline L-APB & $10 \pm 8$ & $62 \pm 5^{h}$ & $\uparrow 9 \pm 12$ & $\uparrow 2 \pm 9$ \\
\hline D-APB & $6 \pm 9$ & $33 \pm 6^{b}$ & $\uparrow 3 \pm 9$ & $\uparrow 2 \pm 4$ \\
\hline L-Glutamate & $102 \pm 2$ & $98 \pm 1$ & $91 \pm 11$ & $86 \pm 6$ \\
\hline D-Glutamate & $41 \pm 13$ & $63 \pm 9^{b}$ & $9 \pm 8$ & $16 \pm 12$ \\
\hline L-Aspartate & $82 \pm 3$ & $83 \pm 3$ & $94 \pm 12$ & $82 \pm 6$ \\
\hline D-Aspartate & $36 \pm 12$ & $57 \pm 10$ & $14 \pm 12$ & $19 \pm 6$ \\
\hline
\end{tabular}

${ }^{a} p<0.01$ for the significance of difference between zero $\mathrm{CaCl}_{2}$ and $2.5 \mathrm{mM} \mathrm{CaCl}_{2}$ conditions (paired $t$ test).

${ }^{b} p<0.05$ for the significance of difference between zero $\mathrm{CaCl}_{2}$ and $2.5 \mathrm{mM} \mathrm{CaCl}_{2}$ conditions (paired $t$ test).

the $\mathrm{L}$ form. The binding of L-aspartate was not affected significantly by any of these substances either in the presence or absence of $\mathrm{CaCl}_{2}$.

Additional experiments using the stereoisomers of glutamate and aspartate $(0.1 \mathrm{~mm}$ concentration) suggested that $\mathrm{CaCl}_{2}$ did not alter the inhibitory potencies of the $\mathrm{L}$ isomers (see also next section), but it did increase the effectiveness of the $\mathrm{D}$ forms $(p<0.05$ for D-glutamate; Table I). In the case of L-aspartate binding, the $\mathrm{L}$ isomers of both glutamate and aspartate were better inhibitors than their $\mathrm{D}$ enantiomers, and $\mathrm{CaCl}_{2}$ had no effect on the activity of any of these substances.

Kinetics of inhibition of $L$-glutamate binding by phosphonic acid derivatives in the presence of $\mathrm{CaCl}_{2}$. Scatchard analyses indicated that, at low concentrations (10 $\mu \mathrm{M})$, DL-APB inhibited L-glutamate binding competitively (no change in $B_{\max }$; increase in apparent $K_{D}$ ), whereas the inhibition kinetics deviated from competitive type behavior at higher concentrations (Fig. 1a). More extensive analyses, using a wide range of inhibitor concentrations, demonstrated that this deviation was due to the presence of a DL-APB-insensitive component of L-glutamate binding (i.e., a glutamate binding component which persisted in the presence of high concentrations of APB; see Fig. $1 b$ ). Similar plots indicated that DL-APB, its stereoisomers, and DL-APV all competed with different affinities for the same L-glutamate binding site, which represented about $80 \%$ of the L-glutamate bound (Fig. $1 b$ ). The $K_{i}$ values calculated from these plots showed that the order of potency for the inhibition of L-glutamate binding was APB > APV > APP, with L-APB 15-fold more potent than its D enantiomer (Table II). Moreover, with the exception of APV, which appears to be a potent 

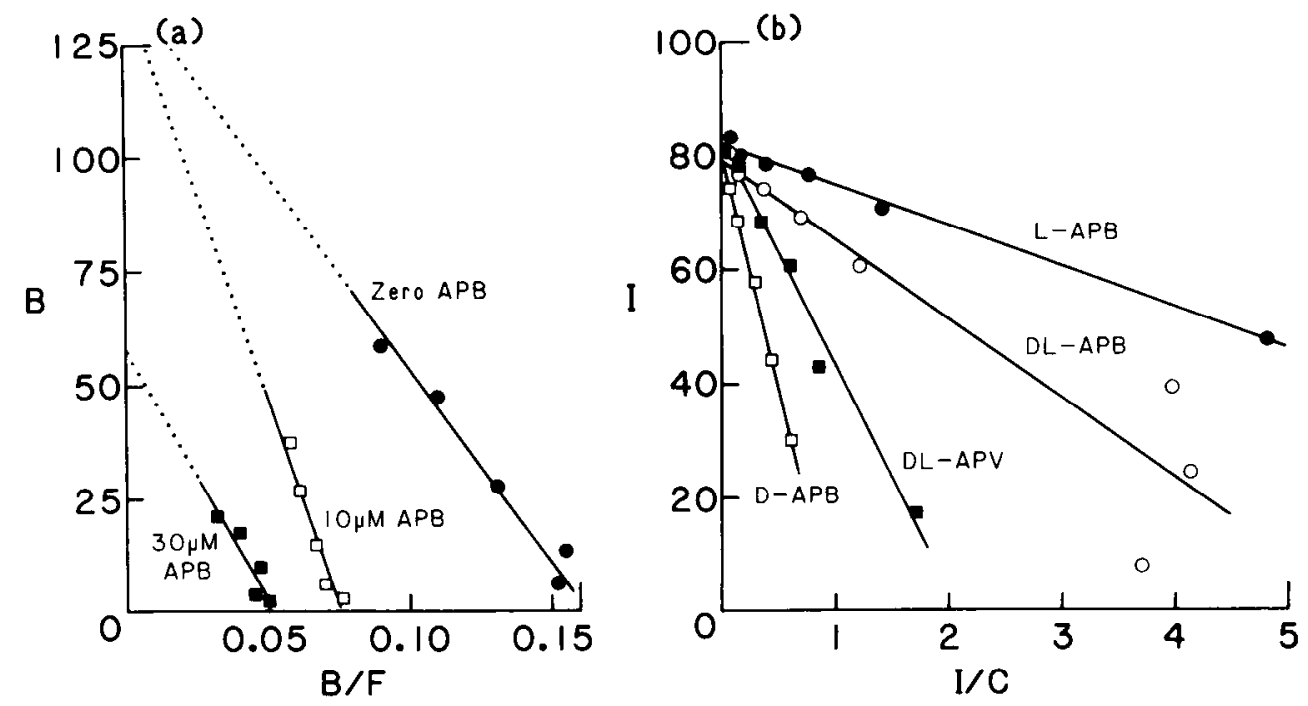

Figure 1. Inhibition of specific L- $\left[{ }^{3} \mathrm{H}\right]$ glutamate binding by phosphonic acid derivatives. SPMs were isolated from rat forebrains and L-glutamate binding was assayed in the presence of $2.5 \mathrm{mM} \mathrm{CaCl}_{2}$ as described under "Materials and Methods." $a$, Scatchard plots of specific L-glutamate binding in the absence $(O)$ and presence of $10 \mu \mathrm{M}(\square)$ and $30 \mu \mathrm{M}$ (a) DL-APB. Binding was assayed at L-glutamate concentrations of 50 to $750 \mathrm{nM}$. $B$ is the specific binding (picomoles per mg of SPM protein) and $F$ the free concentration (nanomolar) of L-glutamate. $b$, Scatchard plots of the inhibition of specific L-glutamate binding by

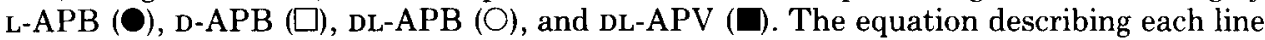
is: $I=I_{\max }-I / C\left(K_{I}\left(1+F / K_{D}\right)\right)$, where $I$ (the amount of inhibitor bound to specific Lglutamate binding sites) is expressed as the percentage of inhibition of specific L-glutamate binding, $I_{\max }$ is the maximum percentage of inhibition, $C$ is the inhibitor concentration (which ranged from 1 to $1000 \mu \mathrm{M}$ in these experiments), $F$ is the free concentration of $L$ $\left[{ }^{3} \mathrm{H}\right]$ glutamate $(50 \mathrm{nM})$, and $K_{D}$ is its dissociation constant. Lines of best fit were determined by linear regression analysis and $K_{I}$ values were calculated as described in the legend to Table II. Each plot is representative of those obtained in two to five separate experiments (see Table II for additional details), and each point is the mean of triplicate determinations.

inhibitor of NMDA-induced responses in the spinal cord (Davies et al., 1981), these values are in close agreement with those determined for the antagonism of perforant path-evoked field potentials in the outer molecular layer of the rat dentate gyrus in vitro (Koerner and Cotman, 1981; see Table II). Similar analyses using L-glutamate as the inhibitor of binding yielded a $K_{I}$ value of $0.75 \mu \mathrm{M}$, which is the same as that determined in the absence of $\mathrm{CaCl}_{2}(0.77 \mu \mathrm{M})$ and is in close agreement with $K_{D}$ estimates for radiolabeled L-glutamate in a variety of synaptic membrane preparations (Foster and Roberts, 1978; Baudry and Lynch, 1979; Foster et al., 1981b). Hill coefficients for the phosphonic acid derivatives and for $L$ glutamate ( 0.90 to 1.10 , Table II) indicated an absence of cooperative interactions.

In order to determine whether the approximately $20 \%$ APB-resistant L-glutamate binding sites observed in the presence of $\mathrm{CaCl}_{2}$ could be equated with the $\mathrm{CaCl}_{2}$-independent sites, a comparison was made of the residual L-glutamate binding after inhibition by APB in the two assay conditions $\left( \pm \mathrm{CaCl}_{2}\right)$. In the presence of $0.1 \mathrm{mM} \mathrm{L}$ APB (a concentration giving near maximal inhibition), the amount of L-glutamate bound to SPMs was similar whether $\mathrm{CaCl}_{2}$ was included in the assay buffer or not (zero $\mathrm{CaCl}_{2}, 1.51 \pm 0.45 \mathrm{pmol} / \mathrm{mg}$ of protein; $2.5 \mathrm{~mm}$ $\mathrm{CaCl}_{2}, 1.70 \pm 0.47 \mathrm{pmol} / \mathrm{mg}$ of protein; $n=6$ ) despite the observation that the specific L-glutamate binding was augmented more than 3-fold by these ions. Hence, the increase in L-glutamate binding induced by $\mathrm{CaCl}_{2}$ appears to represent the introduction of a new population of L-glutamate binding sites which are selectively sensitive to inhibition by APB.

Effects of $\mathrm{Cl}^{-}$and $\mathrm{Ca}^{2+}$ alone and in combination on $A P B$-sensitive $L$-glutamate binding. Recent observations in this laboratory have shown that $\mathrm{Cl}^{-}$stimulates L-glutamate binding to SPMs and that $\mathrm{Ca}^{2+}$ acts only in the presence of $\mathrm{Cl}^{-}$to enhance this response further (Mena et al., 1982). The pharmacological studies reported here were conducted in the presence of both $\mathrm{Cl}^{-}$and $\mathrm{Ca}^{2+}\left(\right.$ as $\left.\mathrm{CaCl}_{2}\right)$, and the data presented in the preceding section indicate that the additional binding sites revealed by these ions in combination were of the APB-sensitive type. Further experiments to define the role of each ion demonstrated that the $K_{I}$ values for the inhibition of $\mathrm{L}$ glutamate binding by DL-APB were similar (parallel lines in Scatchard plots) both when $5 \mathrm{mM} \mathrm{Cl}^{-}$(as Tris-Cl) and when $5 \mathrm{mM} \mathrm{Cl}^{-}$plus $2.5 \mathrm{~mm} \mathrm{Ca}^{2+}$ (as $2.5 \mathrm{~mm} \mathrm{CaCl}_{2}$ ) were included in the assay buffer (Fig. 2). However, almost 2fold more APB-sensitive sites were apparent in the presence of $\mathrm{CaCl}_{2}$ than in the presence of $\mathrm{Cl}^{-}$alone. In the presence of only $2.5 \mathrm{mM} \mathrm{Ca}{ }^{2+}$ (added as the acetate salt) or in the absence of added ions, a small number of APBsensitive L-glutamate binding sites were detected (Fig. 2; Table I) possibly due to the presence of residual $\mathrm{Cl}^{-}$and/ or $\mathrm{Ca}^{2+}$ in the SPM preparation.

Additional experiments using a single concentration 
TABLE II

The inhibition of L-glutamate binding and synaptically evoked responses by phosphonic acid derivatives: Summary of kinetic constants SPMs were isolated from rat forebrains and specific L-glutamate binding was assayed in the presence of $2.5 \mathrm{mM}^{\mathrm{CaCl}} \mathrm{Cas}_{2}$ described under "Materials and Methods." Inhibitory compounds were included in the assay buffer at concentrations of 0.1 to $50 \mu \mathrm{M}$ for L-glutamate or 1 to 1000 $\mu \mathrm{M}$ for the phosphonic acid derivatives. $K_{I}^{\prime}$ and $I_{\max }$ values were determined by Scatchard analysis (see Fig. $2 b$ ) and Hill coefficients were from Hill plots (not shown). The $K_{I}$ values tabulated were calculated from the relationship: $K_{I}^{\prime}=K_{I}\left(1+F / K_{D}\right)$, where $F$ is the free concentration of $\mathrm{L}$ - $\left[{ }^{3} \mathrm{H}\right]$ glutamate $(50 \mathrm{nM})$ and $K_{D}$ is its dissociation constant $\left(814 \mathrm{nM}\right.$; Foster et al., 1981b). $I_{\max }$ is expressed as the maximum percentage of inhibition of specific L-glutamate binding. The values are the means \pm SEM of data from $n$ separate experiments; individual determinations are shown in parentheses when $n=2$.

\begin{tabular}{|c|c|c|c|c|c|}
\hline \multirow{2}{*}{ Compound } & \multirow{2}{*}{$\frac{\text { Synaptic Response }}{K_{i}^{a}}$} & \multicolumn{4}{|c|}{ L-Glutamate Binding } \\
\hline & & $\boldsymbol{K}_{\boldsymbol{I}}$ & $I_{\max }$ & Hill Coefficient & $n$ \\
\hline & $\mu M$ & $\mu M$ & $\%$ & & \\
\hline DL-APP & 5000 & $>1000^{b}$ & $\mathrm{ND}^{c}$ & ND & 3 \\
\hline DL-APB & $\mathrm{ND}^{e}$ & $16 \pm 7$ & $82 \pm 3$ & $0.98 \pm 0.04$ & 5 \\
\hline DL-APV & 250 & $39(37,40)$ & $84(83,85)$ & $1.09(1.06,1.11)$ & 2 \\
\hline L-APB & 2.5 & $5 \pm 1$ & $81 \pm 3$ & $0.90 \pm 0.02$ & 3 \\
\hline D-APB & 100 & $75 \pm 15$ & $80 \pm 4$ & $1.07 \pm 0.12$ & 3 \\
\hline L-Glutamate & ND & $0.75(0.68,0.81)$ & $97(97,97)$ & $1.10(1.02,1.18)$ & 2 \\
\hline
\end{tabular}

"Apparent $K_{I}$ values for the antagonism of perforant path-evoked field potentials in the outer molecular layer of the rat dentate gyrus in vitro (calculated from Koerner and Cotman, 1981).

" $1 \mathrm{mM}$ DL-APP inhibited specific L-glutamate binding by $11 \pm 6 \%(n=3)$.

"ND, not determined.

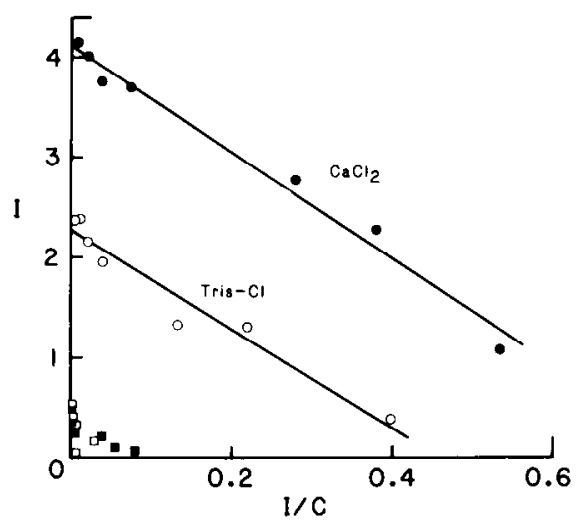

Figure 2. Scatchard plots describing the effects of $\mathrm{Cl}^{-}$and $\mathrm{Ca}^{2+}$ on APB-sensitive L-glutamate binding. SPMs were isolated from rat forebrains, and L-glutamate binding was assayed (50 nM L- $\left[{ }^{3} \mathrm{H}\right]$ glutamate) in buffer alone ( $\square$ ) or in the presence of $2.5 \mathrm{mM} \mathrm{Ca}^{2+}$ (as the acetate salt, $\square$ ), of $5 \mathrm{mM} \mathrm{Cl}^{-1}$ (as Tris-Cl, $\bigcirc$ ), or of $2.5 \mathrm{mM} \mathrm{Ca}^{2+}$ plus $5 \mathrm{~mm} \mathrm{Cl}$ (as $\mathrm{CaCl}_{2}, \quad$ ). $I$ is the amount (picomoles per $\mathrm{mg}$ of SPM protein) of L-glutamate bound to APB-sensitive sites at concentrations $(C$ ) of DL-APB ranging from 1 to $500 \mu \mathrm{M}$. Lines of best fit were determined by linear regression analysis. Each line is representative of those obtained in two or three separate experiments, and each point is the mean of triplicate determinations. In the experiment illustrated, the total specific binding of $\mathbf{L}$-glutanate under each condition was: buffer alone, $1.14 \mathrm{pmol} / \mathrm{mg}$ of protein; $2.5 \mathrm{mM}$ $\mathrm{Ca}^{2+}, 1.03 \mathrm{pmol} / \mathrm{mg}$ of protein; $5 \mathrm{mM} \mathrm{Cl}{ }^{-}, 3.01 \mathrm{pmol} / \mathrm{mg}$ of protein; and $2.5 \mathrm{~mm} \mathrm{Ca}{ }^{2+}$ plus $5 \mathrm{~mm} \mathrm{Cl} \mathrm{Cl}^{-}, 4.67 \mathrm{pmol} / \mathrm{mg}$ of protein.

(0.2 $\mathrm{mm}$ ) of DL-APB to assess APB-sensitive L-glutamate binding indicated that either pretreatment of SPMs with EDTA (see "Materials and Methods") or inclusion of 10 mM FD'TA in the assay buffer (1) abolished the small degree of APB sensitivity observed in the absence of added ions (see Table I) and (2) reduced (but did not abolish) the number of APB-sensitive sites induced by 5 $\mathrm{mM} \mathrm{Cl}^{-}$(data not shown). Together, these data suggest
TABLE III

Pharmacological characteristics of $L$-glutamate binding to SPMS SPMs were isolated from rat forebrains and specific L-glutamate binding was assayed as described under "Materials and Methods." $\mathrm{CaCl}_{2}(2.5 \mathrm{~mm})$ and the inhibitory compounds being tested $(0.1 \mathrm{mM}$ final concentration) were included in the assay buffer as appropriate. The values are the means \pm SEM of data from four to eight separate experiments.

\begin{tabular}{lcc}
\hline \multirow{2}{*}{ Compound } & \multicolumn{2}{c}{ Percent Inhibition of Specific Binding } \\
\cline { 2 - 3 } & Zero $\mathrm{CaCl}_{2}$ & $2.5 \mathrm{mM} \mathrm{CaCl}_{2}$ \\
\hline L $\alpha \mathrm{AA}$ & $62 \pm 3$ & $81 \pm 3^{a}$ \\
Ibotenate & $52 \pm 7$ & $77 \pm 5^{b}$ \\
Quisqualate & $53 \pm 9$ & $73 \pm 6^{a}$ \\
D $\alpha$ AA & $48 \pm 11$ & $71 \pm 5^{a}$ \\
ADCP & $26 \pm 10$ & $62 \pm 7^{a}$ \\
DAP & $17 \pm 6$ & $44 \pm 6^{b}$ \\
$\gamma D G G$ & $39 \pm 6$ & $41 \pm 4$ \\
NMA & $29 \pm 12$ & $13 \pm 2$ \\
PDA & $19 \pm 5$ & $8 \pm 4^{a}$ \\
Kainate & $1 \pm 8$ & $2 \pm 3$ \\
\hline
\end{tabular}

${ }^{a} p<0.05$ for the significance of difference between zero $\mathrm{CaCl}_{z}$ and $2.5 \mathrm{mM} \mathrm{CaCl} 2$ conditions (paired $t$ test).

${ }^{b} p<0.01$ for the significance of difference between zero $\mathrm{CaCl}_{2}$ and $2.5 \mathrm{mM} \mathrm{CaCl}_{2}$ conditions (paired $t$ test).

that $\mathrm{Cl}^{-}$is necessary to unmask the APB-sensitive population of L-glutamate binding sites in SPMs and that $\mathrm{Ca}^{2+}$ is required to reveal the full extent of this response.

General pharmacological characteristics of $\mathrm{CaCl} \mathrm{Cl}_{2}$-dependent $L$-glutamate binding. In addition to the phosphonic acid derivatives, the pharmacological specificity of L-glutamate binding in the presence of $\mathrm{CaCl}_{2}$ was assessed using a number of analogues which, through electrophysiological studies, have been proposed as agonists or antagonists of the various excitatory amino acid receptor classes (see, for example, McLennan, 1981; Watkins and Evans, 1981). At a concentration of $0.1 \mathrm{~mm}$, quisqualate, ibotenate, D $\alpha \mathrm{AA}$, and L $\alpha \mathrm{AA}$ inhibited greater than $70 \%$ of the L-glutamate binding in the pres- 
TABLE IV

Subcellular distribution of $\mathrm{CaCl}_{2}$-dependent (APB-sensitive) L-glutamate binding sites

Subcellular fractions were isolated from rat forebrains and L-glutamate binding was assayed as described under "Materials and Methods." Assays were carried out in the presence of $2.5 \mathrm{mM} \mathrm{CaCl}_{2}$ using $0.1 \mathrm{~mm}$ DL-APB to determine the APB-sensitive $\left(\mathrm{CaCl}_{2}\right.$-dependent) component of $\mathrm{L}$-glutamate binding. The values are the means \pm SEM of data from three or four separate experiments.

\begin{tabular}{lcc}
\hline \multirow{2}{*}{ Fraction } & \multicolumn{2}{c}{ Amount of L-Glutamate Bound } \\
\cline { 2 - 3 } & $\begin{array}{c}\text { Picunules per } \\
\text { mg of Protein }\end{array}$ & $\begin{array}{c}\text { Relative to } \\
\text { Particulate }\end{array}$ \\
\hline Particulate & $1.82 \pm 0.25$ & 1 \\
P. $_{2}$ & $2.41 \pm 0.14$ & 1.32 \\
INT-P. & $2.87 \pm 0.58$ & 1.58 \\
SPM & $4.15 \pm 1.18$ & 2.28 \\
\hline
\end{tabular}

ence of $\mathrm{CaCl}_{2}$ and were significantly more effective than in the absence of these ions (Table III). At the opposite end of the potency range, NMA, kainate, and PDA displaced less than $15 \%$ of the binding in the presence of $\mathrm{CaCl}_{2}$; the effect of PDA was significantly lower than in the absence of $\mathrm{CaCl}_{2}$, whereas kainate and NMA inhibitions were unchanged (although the mean value for NMA was somewhat lower in the $\mathrm{CaCl}_{2}$ condition). The remaining compounds (ADCP, $\gamma \mathrm{DGG}$, and DAP) produced inhibitions in the presence of $\mathrm{CaCl}_{2}$ of 40 to $65 \% ; \mathrm{CaCl}_{2}$ markedly increased the effectiveness of ADCP and DAP, whereas the potency of $\gamma \mathrm{DGG}$ was unaffected by these ions (Table III). GABA and its analogue, baclofen, at concentrations of $0.1 \mathrm{mM}$, were ineffective as displacers of $\mathrm{L}$-glutamate binding both in the presence and absence of $\mathrm{CaCl}_{2}$ (data not shown).

Subcellular localization of $\mathrm{CaCl}_{2}$-dependent (APBsensitive) L-glutamate binding sites. The data presented above suggest that $\mathrm{CaCl}_{2}$-dependent $\mathrm{L}$-glutamate binding sites are of functional significance at acidic amino acidusing synapses in the brain, and therefore, one would predict a higher density of these sites in synaptic membranes than in other cellular organelles. Analyses of total particulate, crude mitochondrial $\left(\mathrm{P}_{2}\right)$, and SPM fractions indicated a progressive enrichment of $\mathrm{CaCl}_{2}$-dependent (APB-sensitive) sites as nonsynaptic material was removed, with the density of sites in SPMs being more than 2 -fold greater than in the particulate fraction (Table IV). Table IV also shows that INT, a mild oxidizing agent which is used to facilitate the separation of mitochondria from SPMs (see "Materials and Methods"), does not affect the binding of $\mathrm{L}$-glutamate to $\mathrm{CaCl}_{2}$-dependent (APB-sensitive) sites $\left(p<0.2\right.$ between $\mathrm{P}_{2}$ and INT- $\mathrm{P}_{2}$ fractions; paired $t$ test).

\section{Discussion}

The findings of this study are of considerable significance both for investigations of glutamate binding and for an understanding of the molecular mechanisms involved in acidic amino acid-mediated synaptic transmission. Our data provide the first evidence for the identity of a population of SPM-located L-glutamate binding sites with receptors at a specific synapse and suggest that $\mathrm{Cl}^{-}$ and $\mathrm{Ca}^{2+}$ ions serve important functions at acidic amino acid-using synapses in the CNS.
The observations presented here demonstrate that there are two populations of $\mathrm{Na}^{+}$-independent L-glutamate binding sites in SPMs which can be distinguished on the basis of their $\mathrm{Cl}^{-}$and $\mathrm{Ca}^{2+}$ requirements and their pharmacological characteristics, although $K_{D}$ (Foster et al., 1981b) and $K_{I}$ determinations (this paper) in the presence and absence of $\mathrm{CaCl}_{2}$ suggest that the affinities of these sites for L-glutamate are similar. The $\mathrm{Cl}^{-} / \mathrm{Ca}^{2+}$. dependent sites described in this report exhibit a number of properties indicative of a role as synaptic receptors. Fundamental to this postulate is the observation that their pharmacological specificity (assessed using a series of phosphonic acid derivatives) is in close agreement with that determined electrophysiologically at the perforant path-granule cell synapse in the rat dentate gyrus (Koerner and Cotman, 1981; see Table II), where glutamate is probably the neurotransmitter (Cotman and Nadler, 1981). In addition, the sites were sensitive to inhibition by a number of compounds with agonist (e.g., quisqualate, ibotenate, and ADCP) or antagonist (e.g., $\mathrm{D} \alpha \mathrm{AA}$ and $\mathrm{APB}$ ) activity at acidic amino acid receptor sites (see Watkins and Evans, 1981). The $\mathrm{Cl}^{-} / \mathrm{Ca}^{2+}$-dependent sites were shown to be enriched in SPMs (relative to unfractionated brain membranes) and, consistent with the hypothesis that acidic amino acids serve widespread transmitter functions in the CNS (Curtis and Johnston, 1974), were present at high levels in the whole forebrain SPMs employed for this investigation (although note that there is a nonuniform distribution of these sites in the brain, with high densities in the hippocampus and brain stem; Monaghan et al., 1981). Hence, the data presented here constitute a firm basis for proposing that the $\mathrm{Cl}^{-} / \mathrm{Ca}^{2+}$-dependent (APB-sensitive) Lglutamate binding sites are of physiological significance at acidic amino acid-using synapses in the CNS.

A number of investigators have shown previously that $\mathrm{Ca}^{2+}$ augments the binding of L-glutamate to various SPM preparations (Michaelis et al., 1974; Baudry and Lynch, 1979; Vargas and Costa, 1981) and that APB is an inhibitor of similar potency to that reported here (Foster and Roberts, 1978; Baudry and Lynch, 1981). In all of these studies, $\mathrm{Cl}^{-}$-containing buffers were utilized for the binding assay. In one investigation employing Tris-citrate buffer (Biziere et al., 1980), APB was demonstrated to be of lower potency, and the general pharmacological profile for L-glutamate binding was somewhat different from that described by other authors (Foster and Roberts, 1978; Baudry and Lynch, 1981). The findings of the present study, that there are two pharmacologically distinct populations of L-glutamate binding sites, one of which is revealed in the presence of $\mathrm{Cl}^{-}$(and $\mathrm{Ca}^{2+}$ ), help to reconcile these discrepancies.

The observation that $\mathrm{Cl}^{-}$stimulates L-glutamate binding to APB-sensitive sites was unexpected and merits discussion. Interestingly, those anions which mediate this effect (Mena et al., 1982) are the same anions which both modify the interaction of GABA antagonists (Enna and Snyder, 1977; Mohler and Okada, 1978) and benzodiazepines (Costa et al., 1979) with their recognition sites and permeate the neuronal membrane during postsynaptic inhibition (Araki et al., 1961). In the GABA-benzodiazepine system, the receptor sites are thought to be linked to the membrane $\mathrm{Cl}^{-}$ion channel (Olsen, 1981). By 
analogy, one possibility is that those L-glutamate binding sites stimulated by $\mathrm{Cl}^{-}$(the APB-sensitive population) also are associated with a $\mathrm{Cl}^{-}$ionophore (note that this does not exclude a glutamate action at other receptor sites (APB-insensitive sites?) to produce a more classical $\mathrm{Na}^{+}$-mediated excitatory response). This proposal gains credence from a number of observations: (1) iontophoretic application of glutamate occasionally has been reported to inhibit neuronal firing (Yamamoto et al., 1976; Spencer et al., 1978); (2) the reversal potential for glutamate responses cannot be explained simply on the basis of $\mathrm{Na}^{+}$conductance and conceivably could involve a $\mathrm{Cl}^{-}$ component (Wojtowicz et al., 1981); and (3) at the photoreceptor-ON bipolar cell synapse in the retina, APB recently has been shown to mimic the hyperpolarizing actions of the natural transmitter (glutamate?) (Slaughter and Miller, 1981), possibly by decreasing $\mathrm{Cl}^{-}$conductance (Miller and Dacheux, 1976). In the retinal system, the potencies of the phosphonic acid homologues $\left(\mathrm{EC}_{50}\right.$ values for inhibition of acetylcholine release from amacrine cells; Neal et al., 1981) closely resemble those obtained in this study and by Koerner and Cotman (1981) for the antagonism of perforant path-granule cell synaptic transmission in the dentate gyrus. At this latter synapse, however, it is currently not clear whether APB acts pre- or postsynaptically to reduce the granule cell response. Here, as in the olfactory cortex (Hori et al., 1981) and in the spinal cord (Evans et al., 1981), APB does not antagonize the response to iontophoretically applied glutamate (E. W. Harris, A. H. Ganong and C. W. Cotman, unpublished observations), suggesting that a postsynaptic action is less likely. The hypothesis that APB acts on a specific population of presynaptic L-glutamate receptors to reduce transmitter release remains to be evaluated.

\section{References}

Araki, T., M. Ito, and O. Oscarsson (1961) Anion permeability of the synaptic and non-synaptic motoneurone membrane. J. Physiol. (Lond.) 159: 410-435.

Ault, B., R. H. Evans, A. A. Francis, D. J. Oakes, and J. C. Watkins (1980) Selective depression of excitatory amino acid induced depolarizations by magnesium ions in isolated spinal cord preparations. J. Physiol (Lond.) 307: 413-428.

Baudry, M., and G. Lynch (1979) Regulation of glutamate receptors by cations. Nature 282: 748-750.

Baudry, M., and G. Lynch (1980) Regulation of hippocampal glutamate receptors: Evidence for the involvement of a calcium-activated protease. Proc. Natl. Acad. Sci. U. S. A. 77: 2298-2302.

Baudry, M., and G. Lynch (1981) Hippocampal glutamate receptors. Mol. Cell. Biochem. 38: 5-18.

Biziere, C., H. Thompson, and J. T. Coyle (1980) Characterization of specific high-affinity binding sites for $\mathrm{L}-\left[{ }^{3} \mathrm{H}\right]$ glutamic acid in rat brain membranes. Brain Res. 183: 421-433.

Custa, T., D. Rodbard, and C. B. Pert (1979) Is the benzodiazepine receptor coupled to a chloride anion channel? Nature 277: 315-317.

Cotman, C. W., and J. V. Nadler (1981) Glutamate and aspartate as hippocampal transmitters: Biochemical and pharmacological evidence. In Glutamate: Transmitter in the Central Nervous Sytem, P. J. Roberts, J. Storm-Mathisen, and G. A. R. Johnston, eds., pp. 117-154, John Wiley and Sons, New York.

Cotman, C. W., and D. Taylor (1972) Isolation and structural studies on synaptic complexes from rat brain. J. Cell Biol. 55: 696-711.

Cotman, C. W., A. C. Foster, and T. H. Lanthorn (1981) An overview of glutamate as a neurotransmitter. In Glutamate as a Neurotransmitter, G. DiChiara and G. L. Gessa, eds., pp. 1-27, Raven Press, New York.

Curtis, D. R., and G. A. R. Johnston (1974) Amino acid transmitters in the mammalian CNS. Ergeb. Physiol. Biol. Chem. Exp. Pharmakol. 69: 97-188.

Davies, J., and J. C. Watkins (1979) Selective antagonism of amino acid-induced and synaptic excitation in the cat spinal cord. J. Physiol. (Lond.) 297: 621-635.

Davies, J., A. A. Francis, A. W. Jones, and J. C. Watkins (1981) 2-Amino-5-phosphonovalerate (2APV), a potent and selective antagonist of amino acid-induced and synaptic excitation. Neurosci. Lett. 21: 77-81.

Enna, S. J., and S. H. Snyder (1977) Intluences of ions, enzymes and detergents on $\gamma$-aminobutyric acid-receptor binding in synaptic membranes of rat brain. Mol. Pharmacol. 13: 442453.

Evans, R. H., A. W. Jones, and J. C. Watkins (1981) Depressant action of the L-glutamate analogue $(+) 2$-amino-4-phosphonobutyrate. Br. J. Pharmacol. 74: 907P.

Fagg, G. E., A. C. Foster, E. E. Mena, J. F. Koerner, and C. W. Cotman (1981) Calcium ions and the pharmacology of acidic amino acid receptor sites. Trans. Am. Soc. Neurochem. 12: 122.

Foster, A. C., and P. J. Roberts (1978) High affinity L- $\left[{ }^{3} \mathrm{H}\right]$ glutamate binding to postsynaptic receptor sites on rat cerebellar membranes. J. Neurochem. 31: 1467-1477.

Foster, A. C., E. E. Mena, G. E. Fagg, and C. W. Cotman (1981a) Glutamate and aspartate binding sites are enriched in synaptic junctions isolated from rat brain. J. Neurosci. 1: 620-625.

Foster, A. C., G. E. Fagg, E. E. Mena, and C. W. Cotman (1981b) L-Glutamate and L-aspartate bind to separate sites in rat brain synaptic membranes. Brain Res. 229: 246-250.

Greenberg, D. A., D. C. U'Prichard, P. Sheehan, and S. H. Snyder (1978) $\alpha$-Noradrenergic receptors in the brain: Differential effects of sodium on the binding of ${ }^{3} \mathrm{H}$-agonists and antagonists. Brain Res. 140: 378-384.

Hill, D. R., and N. G. Bowery (1981) ${ }^{3}$ H-Baclofen and ${ }^{3} \mathrm{H}-$ GABA bind to bicuculline-insensitive $\mathrm{GABA}_{B}$ sites in rat brain. Nature 290: 149-152.

Hori, N., C. R. Auker, D. J. Braitman, and D. O. Carpenter (1981) Lateral olfactory tract transmitter: Glutamate, aspartate, or neither. Cell. Mol. Neurobiol. 1: 115-120.

Koerner, J. F., and C. W. Cotman (1981) Micromolar L-2-amino4-phosphonobutyric acid selectively inhibits perforant path synapses from lateral entorhinal cortex. Brain Res. 216: 192198.

London, E. D., and J. T. Coyle (1979) Cooperative interactions at ${ }^{3} \mathrm{H}$-kainic acid binding sites in rat and human cerebellum. Eur. J. Pharmacol. 56: 287-290.

Lowry, O. H., N. J. Rosebrough, L. A. Farr, and R. J. Randall (1951) Protein measurement with the Folin phenol reagent. J. Biol. Chem. 193: 265-275.

McLennan, H. (1981) On the nature of the receptors for various excitatory amino acids in the mammalian central nervous system. In Glatamale as a Neurotransmitter, G. DiChiara and G. L. Gessa, eds., pp. 253-262, Raven Press, New York.

Mena, E. E., G. E. Fagg, and C. W. Cotman (1982) Chloride ions enhance L-glutamate binding to rat brain synaptic membranes. Brain Res., in press.

Michaelis, E. K., M. L. Michaelis, and L. L. Boyarsky (1974) High affinity glutamate binding to brain synaptic membranes. Biochim. Biophys. Acta 367: 338-348.

Michaelis, E. K., M. L. Michaelis, and R. D. Grubbs (1980) Distinguishing characteristics between glutamate and kainic 
acid binding sites in brain synaptic membranes. FEBS Lett. 118: 55-57.

Miller, R. F., and R. F. Dacheux (1976) Synaptic organization and ionic basis of on and off channels in mudpuppy retina. $J$. Gen. Physiol. 67: 639-659.

Mohler, H., and T. Okada (1978) Properties of $\gamma$-aminobutyric acid receptor binding with $(+)-\left[{ }^{3} \mathrm{H}\right]$ bicuculline methiodide in rat cerebellum. Mol. Pharmacol. 14: 256-265.

Monaghan, D. T., A. C. Foster, G. E. Fagg, E. E. Mena, and C. W. Cotman (1981) Characterization and regional distribution of acidic amino acid binding sites in rat brain. Soc. Neurosci. Abstr. 7: 503.

Neal, M. J., J. R. Cunningham, T. A. James, M. Josephs, and J. F. Collins (1981) The effect of 2-amino-4-phosphonobutyrate $(\mathrm{APB})$ on acetylcholine release from the rabbit retina: Evidence for on-channel input to cholinergic amacrine cells. Neurosci. Lett. 26: 301-305.

Olsen, R. W. (1981) GABA-benzodiazepine-barbiturate receptor interactions. J. Neurochem. 37: 1-13.

Pert, C. B., and S. H. Snyder (1974) Opiate receptor binding of agonists and antagonists affected differentially by sodium. Mol. Pharmacol. 10: 868-879.

Roberts, P. J. (1981) Receptors for excitatory amino acids: Binding studies and stimulation of cyclic GMP levels. In Amino Acid Transmitters, P. Mandel and F. V. DeFeudis, eds., Raven Press, New York, in press.

Sharif, N. A., and P. J. Roberts (1981) L-Aspartate binding sites in rat cerebellum: A comparison of the binding of $L-\left[{ }^{3} \mathrm{H}\right]$ aspartate and $\mathrm{L}-\left[{ }^{3} \mathrm{H}\right]$ glutamate to synaptic membranes. Brain Res. 211: 293-303.
Slaughter, M. M., and R. F. Miller (1981) 2-Amino-4-phosphonobutyric acid: A new pharmacological tool for retina research. Science 211: 182-185.

Spencer, II., V. K. Gribkoff, and G. S. Lynch (1978) Distribution of acetylcholine, glutamate and aspartate sensitivity over the dendritic fields of hippocampal CA1 neurons. In Iontophoresis and Transmitter Mechanisms in the Mammalian Central Nervous System, R. W. Ryall and J. S. Kelly, eds., pp. 194-196, Elsevier/North-Holland Biomedical Press, Amsterdam.

Vargas, F, and E. Costa (1981) Regulation of hippocampal glutamate receptors: Role of a calcium-dependent cysteine proteinase. In Glutamate as a Neurotransmitter, G. DiChiara and G. L. Gessa, eds., pp. 307-316, Raven Press, New York.

Vargas, F., L. Greenbaum, and E. Costa (1980) Participation of cysteine proteinase in the high affinity $\mathrm{Ca}^{2+}$-dependent binding of glutamate to hippocampal synaptic membranes. Neuropharmacology 19: 791-794.

Watkins, J. C., and R. H. Evans (1981) Excitatory amino acid transmitters. Annu. Rev. Pharmacol. Toxicol. 21: 165-204.

White, W. F., J. V. Nadler, and C. W. Cotman (1979) The effect of acidic amino acid antagonists on synaptic transmission in the hippocampal formation in vitro. Brain Res. 164: 177-194.

Wojtowicz, J. M., M. Gysen, and J. F. MacDonald (1981) Multiple reversal potentials for response to L-glutamic acid. Brain Res. 213: 195-200.

Yamamoto, C., H. Yamashita, and T. Chujo (1976) Inhibitory action of glutamic acid on cerebellar interneurones. Nature 262: $786-787$. 